\title{
QUALIDADE FISIOLÓGICA DE CIPSELAS DE GIRASSOL EM FUNÇÃO DE LARGURA E ÉPOCA DE SEMEADURA ${ }^{1}$
}

\author{
RAFAEL BRITO DE OLIVEIRA², MARLI A. RANAL ${ }^{3}$, FLÁVIO CAVALCANTE LOPES ${ }^{4}$, \\ ANA VIRGÍNIA DALOSSI OLIVATO ${ }^{5}$
}

\begin{abstract}
RESUMO - O interesse sobre os efeitos do tamanho das sementes no desempenho das plantas tem origem na justificativa dada pelos estudiosos da área de que sementes maiores teriam mais reservas e por isso produziriam plântulas mais vigorosas. Neste sentido, o presente trabalho teve como objetivo analisar a influência da largura de cipselas de girassol, cultivar Helio 360, e da época de semeadura sobre sua qualidade fisiológica. Foram utilizadas cipselas de girassol provenientes de três épocas de semeadura (22 de janeiro, 9 e 12 de julho de 2007), uma realizada no município de Barreiras (BA) e duas no município de São Desidério (BA). As cipselas provenientes de cada uma dessas épocas foram separadas por peneiras de diferentes aberturas, de acordo com a largura $(6,0 ; 5,5 ; 5,0 \mathrm{e} 4,5 \mathrm{~mm})$, sendo determinados o teor de água aos $70{ }^{\circ} \mathrm{C}$ e aos $105^{\circ} \mathrm{C}$ e a qualidade fisiológica por meio dos testes de emergência e vigor de plântulas, em delineamento inteiramente casualizado, esquema fatorial $3 \times 4$. Como o coeficiente de variação, tanto para o teor de água quanto para a matéria seca foi menor aos $70{ }^{\circ} \mathrm{C}$, recomenda-se determinar o teor de água das cipselas nessa temperatura, em função da maior homogeneidade de secagem. Observou-se que com exceção da incerteza, as medidas do processo de emergência e o vigor das plântulas de girassol não mostraram interação significativa entre época de semeadura e largura de cipselas, fatores que não influenciaram na sua qualidade fisiológica. Cipselas de menor largura $(4,5 \mathrm{~mm})$ apresentaram maior teor de água e matéria seca, e menor porcentagem de plântulas normais do que as demais.
\end{abstract}

Termos para indexação: Helianthus annuиs L., vigor, emergência de plântula, teor de água.

\section{PHYSIOLOGICAL QUALITY OF SUNFLOWER CYPSELA AS A FUNCTION OF WIDTH AND SOWING TIME}

\begin{abstract}
Interest in the effect of seed size on plant behavior is due to some researchers believing that larger seeds have more reserves and, consequently, produce more vigorous seedlings. The objective of the present study was to analyze the influence of the width of cipselas from the sunflower cultivar Helio 360, and also sowing time, on their physiological quality. Sunflower cipselas were used from three sowing times (January 22, July 9 and 12, 2007), one located in Barreiras (BA) and two in S. Desiderio (BA). The cipselas from each sowing time were separated using sieves of different sizes (6.0, 5.5, 5.0 and $4.5 \mathrm{~mm}$ widths). Evaluations of the water content at $70{ }^{\circ} \mathrm{C}$ and $105^{\circ} \mathrm{C}$ and the physiological quality, based on seedling emergence and vigor tests,
\end{abstract}

${ }^{1}$ Submetido em 17/06/2010. Aceito para publicação em 09/02/2011.

${ }^{2}$ Eng. Agr., Msc., Pioneer Sementes, rodovia DF 250Km 20, Caixa Postal 08283, CEP 73301-970,Brasília-DF, raf_oliveira@hotmal.com

${ }^{3}$ Bióloga, Dr., Professora Titular, Instituto de Biologia, UFU, Caixa Postal 593, 38400-902. Uberlândia- MG, ranal@ufu.br.
${ }^{4}$ Eng. Agr., Irritech, Avenida Doutor Jaime Ribeiro Luz, 971, sala 33 - Sta. Monica. CEP 38408-188, Uberlândia- MG, flavimlopes@yahoo.com.br.

${ }^{5}$ Eng. Agr., Msc., Heliagro, Avenida Doutor Jaime Ribeiro Luz, 971, sala 19 - Sta. Mônica. CEP 38408-188, Uberlândia- MG, anavirginia@ heliagro.com.br. 
were made using a completely randomized design in a $3 \times 4$ factorial. Since the coefficient of variation for the water content and dry matter was lower at $70{ }^{\circ} \mathrm{C}$, it is recommended that cipselas be dried at this temperature when drying is more uniform. It was observed that with the exception of the uncertainty, there was no significant interaction between sowing time and cipsela width considering measurements of the emergence and vigor of sunflower seedlings, and these factors did not influence cipsela physiological quality. Cipselas with a smaller width $(4.5 \mathrm{~mm})$ had a higher water content and more dry matter and produced a lower percentage of normal seedlings than the others.

Index terms: Helianthus annuus L., vigor, seedling emergence, water content.

\section{INTRODUÇÃO}

Helianthus annuus L. é uma Asteraceae de crescimento rápido, anual, de caule retilíneo, sublenhoso e pouco ramificado no ápice, mais resistente à seca, ao frio e ao calor que a maioria das espécies cultivadas no Brasil (Leite, 2005). Representantes dessa família apresentam frutos do tipo cipsela, pois são oriundos de ovário ínfero, ao contrário dos aquênios, formados a partir de ovários súperos (Marzinek et al., 2008).

A planta do girassol, verde ou ensilada, os grãos, os restos da cultura e os subprodutos gerados durante a extração do óleo, que são de excelente qualidade (Faleiro et al., 2001), podem ser utilizados para a alimentação animal (Tomich et al., 2003; Backes et al., 2008). A alta eficiência em utilizar a água disponível no solo para o seu desenvolvimento, produzindo grande quantidade de matéria seca sob condições de estresse hídrico, bem como sua tolerância à ampla faixa de temperaturas são fatores que estimulam o cultivo do girassol para a produção de forragem após a colheita da safra principal, como cultura de safrinha (Tomich et al., 2003).

A área cultivada com girassol no Brasil saltou de pouco mais de 55 mil hectares em 2001 para 63,6 mil hectares na safra 2009/10 (Conab, 2010). A partir de 2005 esta cultura passou a despertar o interesse de agricultores, técnicos e empresários, devido à possibilidade de se utilizar o seu óleo na fabricação de biodiesel (Embrapa, 2005), o que pode ter motivado esta expansão da área de cultivo ocupada com a cultura.

Há poucas informações disponíveis sobre cultivares adaptadas de girassol e épocas de semeadura apropriadas para as diferentes regiões (Porto et al., 2007). A época de semeadura é um dos principais fatores de sucesso das culturas, incluindo a do girassol, pois além de reduzir o risco de prejuízo devido a doenças, há variação no comportamento de cultivares em função da região (Leite, 2005; Backes et al., 2008).

Trabalhando com girassol, Ungaro et al. (2000) observaram que a época de semeadura normalmente influencia a produção de grãos e a sua composição química. Para as condições de Goiás, boas produções são registradas nas semeaduras de outubro e de fevereiro (Ramos, 1995). Levantamentos feitos por Daros e Ronzelli (1993) para as condições do Paraná e Rio Grande do Sul mostraram que há variações significativas no rendimento em semeaduras realizadas entre setembro e novembro, sendo as maiores produções obtidas na semeadura de setembro. No planalto catarinense, Sangoi e Kruse (1993) encontraram interação significativa entre cultivar e época de semeadura para a produção de cipselas, quantidade de grãos por capítulo, rendimento e massa de 1000 grãos.

As cipselas de girassol, em função das variações que exibem quanto a comprimento, largura e espessura, podem dificultar o trabalho executado pelas semeadoras. Se a classificação dos lotes de acordo com o tamanho dessas cipselas não for efetuada convenientemente, a desuniformidade na distribuição nos sulcos de semeadura pode causar prejuízos ao rendimento potencial das plantas (Marcos Filho et al., 1986). Essa diferença no tamanho das cipselas está associada à diferença no seu desenvolvimento que varia de acordo com a posição das flores no capítulo. Das flores situadas na periferia, desenvolvem-se cipselas consideradas normais, com amêndoa e pericarpo normais. Das flores situadas em direção ao centro do capítulo, as amêndoas diminuem progressivamente de tamanho, chegando-se à situação em que há apenas a formação do pericarpo (Solasi e Mundstock, 1992).

Estudos sobre efeitos do tamanho das sementes no comportamento das plantas em condições de campo têm sido conduzidos para diferentes espécies cultivadas (Leishman e Westoby, 1994). Pesquisando as relações 
existentes entre o tamanho da semente de três cultivares de soja (BRSMG 752S, BRSMG 790A e BRSMG 750SRR) e o vigor das plântulas, Pádua et al. (2010) concluíram que sementes maiores produzem plântulas mais vigorosas. Isso se deve ao fato de que, em geral, sementes de maior tamanho, independente da espécie, são as mais bem nutridas durante seu desenvolvimento. Todavia, em determinadas situações, essas sementes maiores podem não ser as mais vigorosas (Carvalho e Nakagawa, 2000). Segundo Marcos Filho et al. (1986), as pesquisas conduzidas por Adamo et al. (1984), dentre outros, permitiram supor que sementes maiores, melhor dotadas em termos de matéria seca, poderiam originar plantas cujo desenvolvimento inicial fosse mais vigoroso do que as provenientes de sementes pequenas. No entanto, tais autores destacaram decréscimos das diferenças observadas, à medida que as plantas se aproximam do estádio de florescimento, o que também concorda com o que afirmam Carvalho e Nakagawa (2000). Desta forma, a produção final e a qualidade das sementes colhidas não seriam afetadas significativamente. Para o girassol, Marcos Filho et al. (1986) demonstraram que cipselas de tamanho inferior ao tamanho médio do lote apresentam, dentro de limites, tendência à redução da germinação.

O presente trabalho teve como objetivo analisar a influência da largura de cipselas de girassol da cultivar Helio 360 e de diferentes épocas de semeadura sobre sua qualidade fisiológica.

\section{MATERIAL E MÉTODOS}

Cipselas de girassol (Helianthus annuus), cultivar Helio 360 (híbrido triplo, com porcentagem de óleo entre $43 \%$ e $47 \%$, altura média das plantas de $180 \mathrm{~cm}$ a $220 \mathrm{~cm}$ e maturação fisiológica entre 90 e 115 dias), foram colhidas mecanicamente em três campos de produção, irrigados sob sistema de pivô central, com aproximadamente $550 \mathrm{~mm}$ de água. O campo 1 localiza-se no município de Barreiras (BA), entre as coordenadas de $12^{\circ} 08^{\prime} \mathrm{S}$ e $44^{\circ} 59^{\prime} \mathrm{W}$, temperaturas médias anuais entre $20,3{ }^{\circ} \mathrm{C}$ e $32^{\circ} \mathrm{C}$ e altitude média de $452 \mathrm{~m}$. Os campos 2 e 3 , distantes $300 \mathrm{~m}$ entre si, situam-se no município de São Desidério (BA), a $27 \mathrm{~km}$ de Barreiras, entre as coordenadas de $12^{\circ} 22^{\prime}$ S e $44^{\circ} 59^{\prime} \mathrm{W}$, temperaturas médias anuais entre $17^{\circ} \mathrm{C}$ e $38{ }^{\circ} \mathrm{C}$ e altitude média de $400 \mathrm{~m}$.

Esses campos foram produzidos em três épocas, sendo a semeadura do campo $1 \mathrm{em} 22$ de janeiro e a colheita em 13 de junho; a do campo 2 em 9 de julho e a colheita em 8 de novembro e a do campo 3 em 12 de julho, com a colheita em 10 de novembro de 2007. A umidade de colheita das cipselas nos três campos foi de $8,5 \%$. As cipselas do campo 1 ficaram armazenadas durante 10 meses em armazém convencional e as dos campos 2 e 3 durante 5 meses, sem controle de temperatura e umidade relativa do ar, sendo feito somente o monitoramento dessas (temperatura média de $23,4{ }^{\circ} \mathrm{C}$ e umidade relativa de $77 \%$ ). As cipselas provenientes desses campos e épocas de semeadura foram separadas por peneiras de diferentes diâmetros, de acordo com a largura, sendo 6,$0 ; 5,5 ; 5,0$ e 4,5 $\mathrm{mm}$. O termo época será utilizado neste trabalho para, em conjunto, se referir aos campos de produção e épocas de semeadura.

\section{Teor de água}

O teor de água foi calculado para as cipselas oriundas das três épocas de semeadura e das quatro larguras, sendo utilizadas oito repetições de 30 cipselas (massa média de $4,68 \mathrm{~g}$ ) para avaliação em estufa aos $70^{\circ} \mathrm{C}$ e cinco repetições de 30 cipselas (massa média de 4,47 g) para avaliação em estufa aos $105^{\circ} \mathrm{C}$ por 24 horas. O teor de água foi calculado pela expressão:

$$
\text { Teor de água }=(M M F-M M S / M M F) 100 \text {, onde }
$$

$M M F$ : massa da matéria fresca e $M M S$ : massa da matéria seca.

\section{Emergência de plântulas}

Para avaliar a emergência das plântulas, o experimento foi instalado no Jardim Experimental do Instituto de Biologia da Universidade Federal de Uberlândia, em estufa coberta com sombrite, com redução de $50 \%$ na luminosidade. A semeadura foi realizada a $1 \mathrm{~cm}$ de profundidade, em bandejas multicelulares de poliestireno expandido, preenchidas com vermiculita e substrato comercial Plantmax ${ }^{\circledR}$ na proporção $1: 1$, utilizando-se delineamento inteiramente casualizado, em esquema fatorial $3 \times 4$. A semeadura das cipselas oriundas das épocas 2 e 3 foi realizada no dia 14/04/2008 e a da época 1 no dia 16/04/2008. O processo de emergência foi avaliado para as cipselas oriundas das três épocas e das quatro larguras, sendo utilizadas três repetições de 32 cipselas por parcela experimental.

A contagem das plântulas emergidas foi realizada diariamente, adotando-se a emissão do hipocótilo acima do substrato como critério de emergência. A irrigação foi feita diariamente. As temperaturas médias mínimas e máximas do ambiente durante a condução do experimento 
oscilaram entre $18,6{ }^{\circ} \mathrm{C} \pm 1,3$ e $26,7{ }^{\circ} \mathrm{C} \pm 1,5$ (média \pm desvio padrão), respectivamente.

Foi avaliado o tempo para a primeira $\left(\mathrm{t}_{\mathrm{o}}\right)$ e última $\left(\mathrm{t}_{\mathrm{f}}\right)$ emergência de plântulas, sendo o último determinado após a estabilização do evento. Foram calculados ainda a porcentagem $(E)$, o tempo médio $(\overline{\mathrm{t}})$, o coeficiente de variação do tempo $(C V)$, o índice de Maguire $(V E)$, a velocidade média $(\overline{\mathrm{v}})$, a incerteza $(I)$ e a sincronia $(Z)$ do processo de emergência (Ranal e Santana, 2006).

\section{Classificação do vigor da plântula}

O experimento foi conduzido no Laboratório de Análise de Sementes da Universidade Federal de Uberlândia. Foram utilizadas três repetições de 25 cipselas por parcela experimental para cada tratamento (época $\mathrm{x}$ largura). As cipselas foram colocadas para germinar em papel germitest ${ }^{\circledR}$, previamente umedecido com água desmineralizada, confeccionando-se rolos. A quantidade de água em mililitros, utilizada no umedecimento das folhas de papel, foi de três vezes a massa do papel seco. Após a montagem, os rolos foram colocados em germinador tipo Mangelsdorf e mantidos aos $25^{\circ} \mathrm{C}$.

A avaliação das plântulas foi realizada aos cinco dias após a instalação do teste, sendo os resultados expressos em porcentagem de plântulas normais, anormais e de sementes mortas. Procedeu-se à classificação do vigor das plântulas normais em fortes (as que se apresentavam bem desenvolvidas e morfologicamente perfeitas, sem rachaduras ou lesões) e fracas (que apresentavam algum problema em sua estrutura ou possuíam lesões, mas que não caracterizavam anormalidade), segundo Nakagawa (1994). As anormais foram classificadas em danificadas e infeccionadas. Além dessas categorias, foram computadas sementes mortas, sendo que a soma das plântulas normais fortes obtidas representou o vigor. Foram realizadas ainda mensurações do comprimento do hipocótilo e da raiz primária, em cm, das plântulas normais.

\section{Análise estatística}

Para a análise estatística dos dados foram utilizados os testes de Shapiro-Wilk para a normalidade dos resíduos da ANOVA e de Levene para a homogeneidade entre as variâncias $(\alpha \geq 0,01)$. Quando essas duas pressuposições foram atendidas, foi aplicada a análise de variância (ANOVA), seguida pelo teste de Tukey em 0,05 de significância. A falta de normalidade ou homogeneidade (ou ambas) levou à realização de testes não paramétricos, incluindo o teste de Kruskal-Wallis, seguido de Dunn para comparações binárias, a 0,05 de significância.

\section{RESULTADOS E DISCUSSÃO}

Como os coeficientes de variação, tanto para o teor de água quanto para a matéria seca aos $70{ }^{\circ} \mathrm{C}$ foram menores que aos $105{ }^{\circ} \mathrm{C}$ (Tabelas 1 e 2), recomenda-se secar as cipselas na primeira temperatura, pois esta propicia maior homogeneidade de secagem. Cipselas com menor largura (4,5 $\mathrm{mm}$ ), secas aos $70{ }^{\circ} \mathrm{C}$, tiveram maior teor de água e matéria seca nas épocas 1 e 2 e as de maior largura apresentaram maior teor de água nas épocas 2 e 3 (Tabela 1). Apenas na época 3 as cipselas de todas as larguras apresentaram teor de água e massa seca estatisticamente iguais.

Em contrapartida, quando a estufa foi mantida aos $105{ }^{\circ} \mathrm{C}$, o teor de água e a massa seca das cipselas não diferiram, tanto em relação à época de semeadura quanto em relação à largura (Tabela 2). Esses resultados mostram que nuances quanto a essas características são observadas apenas na menor temperatura de determinação do teor de água, o que permite diferenciar a origem das cipselas. Segundo Aguiar et al. (2001), cipselas de girassol da cultivar Catissol 01 apresentaram teor de água diretamente relacionado com o tamanho das cipselas. Estudos realizados por Ferreira e Torres (2000) com sementes de Acacia senegal (L.) Willd. mostraram que sementes maiores apresentaram menor teor de água em relação às menores, o que pode ter sido causado pela remoção de substâncias voláteis juntamente com a água, resultando, assim, em variações na massa da amostra.

Com exceção da incerteza, as medidas do processo de emergência de plântulas de girassol oriundas das três épocas e das quatro larguras estudadas não mostraram interação significativa, ou seja, a emergência de plântulas não foi influenciada pela época de semeadura, nem pela largura das cipselas (Tabelas 3, 4 e, 5). Apenas as cipselas de largura 3 , provenientes da época 2, apresentaram incerteza significativamente maior em relação às demais e não há justificativa quanto a tratos culturais e beneficiamento que expliquem essa diferença (Tabela 5). Estudos realizados por Oliveira et al. (2009) com sementes de carnaúba hospedeira (Copernicia hospita Mart.) e por Ferreira e Torres (2000) com Acacia senegal permitiram concluir que o tamanho de sementes não interferiu no percentual de emergência de plântulas, nem na velocidade de emergência. No entanto, pesquisas conduzidas por Ledo et al. (2002) mostraram que sementes de pupunha (Bactris gasipaes Kunth) grandes e médias apresentam maior velocidade de emergência. 
TABELA 1. Teor de água e massa seca aos $70{ }^{\circ} \mathrm{C}$ de cipselas de girassol da cultivar Helio 360 provenientes de três épocas de semeadura (1: 22 jan., 2: 9 jul., $3: 12$ jul. 2007) e quatro peneiras (1: 6,0 mm, 2: 5,5 mm, 3: 5,0 mm, 4: 4,5 mm).

\begin{tabular}{|c|c|c|c|c|c|c|}
\hline \multirow{5}{*}{$\begin{array}{c}\text { Teor de } \\
\text { água }(\%)\end{array}$} & \multicolumn{6}{|c|}{ Peneira } \\
\hline & Época & 1 & 2 & 3 & 4 & Médias \\
\hline & 1 & $4,41 \pm 0,13 \mathrm{Bb}$ & $5,12 \pm 0,06 \mathrm{Ab}$ & $4,68 \pm 0,10 \mathrm{Bb}$ & $5,53 \pm 0,05 \mathrm{Aa}$ & 4,94 \\
\hline & 2 & $5,88 \pm 0,06 \mathrm{Aa}$ & $5,29 \pm 0,06 \mathrm{Ba}$ & $5,39 \pm 0,79 \mathrm{Ba}$ & $5,55 \pm 0,33 \mathrm{Aa}$ & 5,53 \\
\hline & 3 & $5,38 \pm 0,60 \mathrm{Aa}$ & $5,15 \pm 0,56 \mathrm{Aa}$ & $5,49 \pm 0,59 \mathrm{Aa}$ & $5,33 \pm 0,06 \mathrm{Ab}$ & 5,34 \\
\hline \multicolumn{2}{|c|}{ Médias } & 5,22 & 5,19 & 5,19 & 5,47 & \\
\hline \multicolumn{7}{|c|}{$C V=7,34 ; W=0,6715(<0,0001) ; F=2,5770(0,0072) ; H=72,7890(0,0001)$} \\
\hline \multirow{5}{*}{$\begin{array}{l}\text { Massa seca } \\
(\mathrm{g})\end{array}$} & \multicolumn{6}{|c|}{ Peneira } \\
\hline & Época & 1 & 2 & 3 & 4 & Médias \\
\hline & 1 & $4,61 \pm 0,14 \mathrm{Bb}$ & $5,40 \pm 0,06 \mathrm{Ab}$ & $4,91 \pm 0,10 \mathrm{Bb}$ & $5,85 \pm 0,06 \mathrm{Aa}$ & 5,19 \\
\hline & 2 & $6,24 \pm 0,06 \mathrm{Aa}$ & $5,59 \pm 0,07 \mathrm{Ba}$ & $5,71 \pm 0,90 \mathrm{Ba}$ & $5,88 \pm 0,38 \mathrm{Aa}$ & 5,86 \\
\hline & 3 & $5,69 \pm 0,67 \mathrm{Aa}$ & $5,43 \pm 0,61 \mathrm{Aa}$ & $5,81 \pm 0,67 \mathrm{Aa}$ & $5,63 \pm 0,07 \mathrm{Ab}$ & 5,64 \\
\hline Médias & & 5,51 & 5,47 & 5,48 & 5,79 & \\
\hline \multicolumn{7}{|c|}{$C V=7,84 ; W=0,6672(<0,0001) ; F=2,598(0,0068) ; H=72,789(0,0001)$} \\
\hline
\end{tabular}

TABELA 2. Teor de água e massa seca aos $105{ }^{\circ} \mathrm{C}$ de cipselas de girassol da cultivar Helio 360 provenientes de três épocas de semeadura (1: 22 jan., 2: 9 jul., $3: 12$ jul. 2007) e quatro peneiras (1: 6,0 mm; 2: 5,5 mm; 3: $5,0 \mathrm{~mm} ; 4: 4,5 \mathrm{~mm})$.

\begin{tabular}{|c|c|c|c|c|c|c|}
\hline \multirow{5}{*}{$\begin{array}{l}\text { Teor de } \\
\text { água }(\%)\end{array}$} & \multicolumn{6}{|c|}{ Peneira } \\
\hline & Época & 1 & 2 & 3 & 4 & Médias \\
\hline & 1 & $6,37 \pm 9,88$ & $6,66 \pm 0,07$ & $6,27 \pm 0,04$ & $6,77 \pm 0,26$ & $6,52 \mathrm{a}$ \\
\hline & 2 & $6,50 \pm 0,12$ & $6,52 \pm 0,07$ & $6,22 \pm 0,06$ & $6,10 \pm 0,09$ & $6,34 \mathrm{a}$ \\
\hline & 3 & $6,58 \pm 0,09$ & $6,68 \pm 0,07$ & $6,54 \pm 0,05$ & $6,61 \pm 0,06$ & $6,60 \mathrm{a}$ \\
\hline Médias & & $6,48 \mathrm{~A}$ & $6,62 \mathrm{~A}$ & $6,34 \mathrm{~A}$ & $6,49 \mathrm{~A}$ & \\
\hline \multicolumn{7}{|c|}{$C V=44,01 ; W=0,3263(<0,0001) ; F=4,2720(0,0002) ; H=40,3480(0,0001)$} \\
\hline \multirow{5}{*}{$\begin{array}{c}\text { Massa seca } \\
(\mathrm{g})\end{array}$} & \multicolumn{6}{|c|}{ Peneira } \\
\hline & Época & 1 & 2 & 3 & 4 & Médias \\
\hline & 1 & $7,86 \pm 12,48$ & $7,13 \pm 0,08$ & $6,69 \pm 0,04$ & $7,27 \pm 0,30$ & $7,24 \mathrm{a}$ \\
\hline & 2 & $6,95 \pm 0,14$ & $6,98 \pm 0,08$ & $6,63 \pm 0,06$ & $6,50 \pm 0,10$ & $6,77 \mathrm{a}$ \\
\hline & 3 & $7,05 \pm 0,10$ & $7,15 \pm 0,08$ & $7,00 \pm 0,06$ & $7,08 \pm 0,07$ & 7,07 a \\
\hline Médias & & $7,29 \mathrm{~A}$ & $7,09 \mathrm{~A}$ & $6,77 \mathrm{~A}$ & $6,95 \mathrm{~A}$ & \\
\hline \multicolumn{7}{|c|}{$C V=51,33 ; W=0,3320(<0,0001) ; F=5,0090(0,0001) ; H=40,3480(0,0001)$} \\
\hline
\end{tabular}


TABELA 3. Tempo inicial $\left(t_{o}\right)$, tempo final $\left(t_{f}\right)$ e tempo médio de emergência $(\overline{\mathrm{t}})$ de plântulas de girassol da cultivar Helio 360 provenientes de três épocas de semeadura (1: 22 jan., 2: 9 jul., 3: 12 jul. 2007) e quatro peneiras (1: $6,0 \mathrm{~mm}, 2: 5,5 \mathrm{~mm}, 3: 5,0 \mathrm{~mm}, 4: 4,5 \mathrm{~mm})$.

\begin{tabular}{|c|c|c|c|c|c|c|}
\hline \multirow{5}{*}{$t_{o}(\mathrm{~h})$} & \multicolumn{6}{|c|}{ Peneira } \\
\hline & Época & 1 & 2 & 3 & 4 & Médias \\
\hline & 1 & $95,50 \pm 0$ & $112,17 \pm 6,35$ & $96,17 \pm 12,01$ & $108,50 \pm 0$ & $103,09 \mathrm{a}$ \\
\hline & 2 & $99,83 \pm 7,50$ & $108,50 \pm 0$ & $96,17 \pm 12,01$ & $112,17 \pm 6,35$ & $104,17 \mathrm{a}$ \\
\hline & 3 & $99,83 \pm 7,50$ & $104,17 \pm 7,50$ & $107,83 \pm 21,36$ & $88,17 \pm 18,77$ & $100,00 \mathrm{a}$ \\
\hline \multicolumn{2}{|l|}{ Médias } & $98,39 \mathrm{~A}$ & $108,28 \mathrm{~A}$ & $100,06 \mathrm{~A}$ & $102,95 \mathrm{~A}$ & \\
\hline \multicolumn{7}{|c|}{$C V=10,34 ; W=0,9364(0,0507) ; F=3,89(0,0026) ; H=15,781(0,1494)$} \\
\hline \multirow{5}{*}{$t_{f}(\mathrm{~h})$} & \multicolumn{6}{|c|}{ Peneira } \\
\hline & Época & 1 & 2 & 3 & 4 & Médias \\
\hline & 1 & $183,50 \pm 36,66$ & $203,83 \pm 36,00$ & $136,17 \pm 6,35$ & $219,83 \pm 78,59$ & $185,83 \mathrm{a}$ \\
\hline & 2 & $159,50 \pm 36,66$ & $188,50 \pm 77,15$ & $192,17 \pm 31,37$ & $143,50 \pm 0$ & $170,92 \mathrm{a}$ \\
\hline & 3 & $167,50 \pm 63,50$ & $212,50 \pm 99,92$ & $175,50 \pm 36,66$ & $143,50 \pm 0$ & $174,75 \mathrm{a}$ \\
\hline Médias & & $170,17 \mathrm{~A}$ & $201,61 \mathrm{~A}$ & $167,95 \mathrm{~A}$ & $168,94 \mathrm{~A}$ & \\
\hline \multicolumn{7}{|c|}{$C V=29,37 ; W=0,9499(0,1372) ; F=3,285(0,0072) ; H=11,606(0,394)$} \\
\hline \multirow{5}{*}{$\bar{t}_{(\mathrm{h})}$} & \multicolumn{6}{|c|}{ Peneira } \\
\hline & Época & 1 & 2 & 3 & 4 & Médias \\
\hline & 1 & $120,13 \pm 0,62$ & $123,19 \pm 4,42$ & $115,58 \pm 2,02$ & $138,52 \pm 20,73$ & $124,35 \mathrm{a}$ \\
\hline & 2 & $114,48 \pm 3,34$ & $132,97 \pm 15,06$ & $131,08 \pm 14,51$ & $118,72 \pm 4,06$ & 124,31 a \\
\hline & 3 & $115,71 \pm 5,43$ & $115,89 \pm 3,68$ & $122,69 \pm 15,92$ & $111,78 \pm 1,28$ & $116,52 \mathrm{a}$ \\
\hline Médias & & $116,77 \mathrm{~A}$ & $124,02 \mathrm{~A}$ & $123,12 \mathrm{~A}$ & $123,01 \mathrm{~A}$ & \\
\hline \multicolumn{7}{|c|}{$C V=8,27 ; W=0,9053(0,0049) ; F=4,84(0,0006) ; H=21,782(0,0261)$} \\
\hline
\end{tabular}

Cipselas de menor largura tiveram menor porcentagem de plântulas normais (Tabela 6). No entanto, a largura das cipselas não interferiu no vigor das plântulas de girassol, uma vez que a porcentagem de plântulas normais fortes não diferiu, tanto em relação à época de semeadura quanto em relação à largura, assim como a porcentagem de plântulas anormais danificadas e infectadas e de sementes mortas (Tabelas 6 e 7).
Resultados similares também foram obtidos para a cultivar Continsol de girassol (Adamo et al., 1984). No entanto, estudos realizados por Pádua et al. (2010) com sementes de soja, por Gaspar e Nakagawa (2002) com sementes de milheto (Pennisetum americanum (L.) K. Schum.) e por Santos et al. (2001) com sementes de algodão (Gossypium hirsutum L.) concluíram que as sementes maiores foram mais vigorosas do que as sementes menores. 
TABELA 4. Porcentagem de emergência $(E)$, velocidade média $(\overline{\mathbf{v}})$ e velocidade de emergência $(V E)$ de plântulas oriundas de cipselas de girassol da cultivar Helio 360 provenientes de três épocas de semeadura (1: 22 jan., 2: 9 jul., 3: 12 jul. 2007) e quatro peneiras (1: 6,0 mm, 2: 5,5 mm, 3: 5,0 mm, 4: 4,5 mm).

\begin{tabular}{|c|c|c|c|c|c|c|}
\hline \multirow{5}{*}{$E(\%)$} & \multicolumn{6}{|c|}{ Peneira } \\
\hline & Época & 1 & 2 & 3 & 4 & Médias \\
\hline & 1 & $100 \pm 0$ & $100 \pm 0$ & $98,96 \pm 1,81$ & $94,80 \pm 6,51$ & $98,35 \mathrm{a}$ \\
\hline & 2 & $98,96 \pm 1,80$ & $97,92 \pm 1,80$ & $98,96 \pm 1,80$ & $100 \pm 0$ & 98,96 a \\
\hline & 3 & $100 \pm 0$ & $98,96 \pm 1,80$ & $98,96 \pm 1,80$ & $96,88 \pm 5,41$ & $98,70 \mathrm{a}$ \\
\hline \multicolumn{2}{|l|}{ Médias } & $99,65 \mathrm{~A}$ & $98,96 \mathrm{~A}$ & $98,96 \mathrm{~A}$ & $97,23 \mathrm{~A}$ & \\
\hline \multicolumn{7}{|c|}{$C V=2,79 ; W=0,8723(0,0004) ; F=7,301(0,0001) ; H=4,258(0,9618)$} \\
\hline \multirow{5}{*}{$\bar{v}\left(\mathrm{~h}^{-1}\right)$} & \multicolumn{6}{|c|}{ Peneira } \\
\hline & Época & 1 & 2 & 3 & 4 & Médias \\
\hline & 1 & $0,0083 \pm 0,00004$ & $0,0081 \pm 0,0003$ & $0,0086 \pm 0,0002$ & $0,0073 \pm 0,0010$ & $0,0081 \mathrm{a}$ \\
\hline & 2 & $0,0087 \pm 0,0002$ & $0,0076 \pm 0,0008$ & $0,0077 \pm 0,0008$ & $0,0084 \pm 0,0003$ & $0,0081 \mathrm{a}$ \\
\hline & 3 & $0,0086 \pm 0,0004$ & $0,0086 \pm 0,0003$ & $0,0082 \pm 0,0010$ & $0,0090 \pm 0,0001$ & $0,0086 \mathrm{a}$ \\
\hline \multicolumn{2}{|l|}{ Médias } & $0,0085 \mathrm{~A}$ & $0,0081 \mathrm{~A}$ & $0,0082 \mathrm{~A}$ & $0,0082 \mathrm{~A}$ & \\
\hline \multicolumn{7}{|c|}{$C V=1,10 ; W=0,9203(0,015) ; F=3,478(0,0052) ; H=21,278(0,0306)$} \\
\hline \multicolumn{7}{|c|}{ Peneira } \\
\hline \multirow{4}{*}{$\begin{array}{c}V E \\
\left(\text { plântula.h }{ }^{-1} \text { ) }\right.\end{array}$} & Época & 1 & 2 & 3 & 4 & Médias \\
\hline & 1 & $0,2697 \pm 0,0007$ & $0,2634 \pm 0,0098$ & $0,2754 \pm 0,0026$ & $0,2279 \pm 0,0437$ & $0,2591 \mathrm{a}$ \\
\hline & 2 & $0,2797 \pm 0,0079$ & $0,2483 \pm 0,0162$ & $0,2523 \pm 0,0223$ & $0,2710 \pm 0,0095$ & $0,2628 \mathrm{a}$ \\
\hline & 3 & $0,2795 \pm 0,0108$ & $0,2789 \pm 0,0136$ & $0,2642 \pm 0,0311$ & $0,2801 \pm 0,0136$ & $0,2757 \mathrm{a}$ \\
\hline Médias & & $0,2763 \mathrm{~A}$ & $0,2635 \mathrm{~A}$ & $0,2640 \mathrm{~A}$ & $0,2597 \mathrm{~A}$ & \\
\hline
\end{tabular}

$C V=7,17 ; W=0,9464(0,1062) ; F=3,918(0,0025) ; H=17,679(0,0893)$

$C V$ : coeficiente de variação; $W$ : estatística do teste de Shapiro-Wilk para normalidade dos resíduos da ANOVA; $F$ : estatística do teste de Levene; H: estatística do teste de Kruskal-Wallis. Valores entre parênteses indicam as probabilidades. Médias seguidas da mesma letra maiúscula na linha e minúscula na coluna não diferem entre si pelo teste de Dunn em 0,05 de probabilidade. 
TABELA 5. Coeficiente de variação do tempo $(C V)$, sincronia $(Z)$ e incerteza de emergência $(I)$ de plântulas oriundas de cipselas de girassol da cultivar Helio 360 provenientes de três épocas de semeadura (1: 22 jan., $2: 9$ jul., 3: 12 jul. 2007) e quatro peneiras (1: $6,0 \mathrm{~mm}, 2: 5,5 \mathrm{~mm}, 3: 5,0 \mathrm{~mm}, 4: 4,5 \mathrm{~mm})$.

\begin{tabular}{|c|c|c|c|c|c|c|}
\hline \multirow{5}{*}{$C V_{t}(\%)$} & \multicolumn{6}{|c|}{ Peneira } \\
\hline & Época & 1 & 2 & 3 & 4 & Médias \\
\hline & 1 & $12,64 \pm 3,70$ & $13,57 \pm 5,79$ & $7,36 \pm 1,22$ & $16,20 \pm 4,78$ & $12,44 \mathrm{a}$ \\
\hline & 2 & $11,38 \pm 6,40$ & $24,08 \pm 16,82$ & $20,03 \pm 7,58$ & $7,13 \pm 1,70$ & $15,66 \mathrm{a}$ \\
\hline & 3 & $11,26 \pm 6,28$ & $17,31 \pm 14,24$ & $12,42 \pm 4,91$ & $10,06 \pm 1,37$ & $12,76 \mathrm{a}$ \\
\hline \multicolumn{2}{|l|}{ Médias } & $11,76 \mathrm{~A}$ & $18,32 \mathrm{~A}$ & $13,27 \mathrm{~A}$ & $11,13 \mathrm{~A}$ & \\
\hline \multicolumn{7}{|c|}{$C V(\%)=57,03 ; W=0,9521(0,1611) ;{ }^{1} F=2,332(0,0402) ;{ }^{2} F=1,256(0,3064) ; F c^{*} p=1,302(0,2941)$} \\
\hline \multirow{5}{*}{$Z$} & \multicolumn{6}{|c|}{ Peneira } \\
\hline & Época & 1 & 2 & 3 & 4 & Médias \\
\hline & 1 & $0,45 \pm 0,03$ & $0,58 \pm 0,22$ & $0,47 \pm 0,04$ & $0,32 \pm 0,08$ & $0,45 \mathrm{a}$ \\
\hline & 2 & $0,48 \pm 0,07$ & $0,38 \pm 0,23$ & $0,23 \pm 0,09$ & $0,54 \pm 0,20$ & $0,41 \mathrm{a}$ \\
\hline & 3 & $0,53 \pm 0,09$ & $0,43 \pm 0,12$ & $0,41 \pm 0,15$ & $0,45 \pm 0,11$ & $0,46 \mathrm{a}$ \\
\hline \multicolumn{2}{|l|}{ Médias } & $0,49 \mathrm{~A}$ & $0,46 \mathrm{~A}$ & $0,37 \mathrm{~A}$ & $0,44 \mathrm{~A}$ & \\
\hline \multicolumn{7}{|c|}{$C V(\%)=31,41 ; W=0,9880(0,9699) ;{ }^{1} F=2,2890(0,0436) ;{ }^{2} F=1,501(0,1952) ; F c^{*} p=1,918(0,1188)$} \\
\hline
\end{tabular}

Peneira

\begin{tabular}{ccccccc} 
& Época & 1 & 2 & 3 & 4 & Médias \\
\cline { 2 - 7 }$I$ (bit) & 1 & $1,6666 \pm 0,1193 \mathrm{Aa}$ & $1,0000 \pm 0,4660 \mathrm{Aa}$ & $1,3333 \pm 0,1852 \mathrm{Aa}$ & $2,0000 \pm 0,3262 \mathrm{Aa}$ & 1,4999 \\
& 2 & $1,3333 \pm 0,3208 \mathrm{Aa}$ & $1,3333 \pm 0,2260 \mathrm{Aa}$ & $2,6666 \pm 0,4565 \mathrm{Bb}$ & $1,3333 \pm 0,4779 \mathrm{Aa}$ & 1,6666 \\
& 3 & $1,0000 \pm 0,0971 \mathrm{Aa}$ & $1,3333 \pm 0,3980 \mathrm{Aa}$ & $1,3333 \pm 0,4813 \mathrm{Aa}$ & $1,6667 \pm 0,2946 \mathrm{Aa}$ & 1,3333 \\
\hline
\end{tabular}

\begin{tabular}{|c|c|c|c|c|}
\hline Médias & 1,3333 & 1,2222 & 1,7777 & 1,6666 \\
\hline
\end{tabular}

$C V$ : coeficiente de variação; $W$ : estatística do teste de Shapiro-Wilk para normalidade dos resíduos da ANOVA; ${ }^{1} F$ : estatística do teste de Levene; ${ }^{2} F$ : valor da distribuição de Snedecor (ANOVA); $F c^{*} p$ : valor de $F$ da distribuição de Snedecor para a interação época*peneira. Valores entre parênteses indicam as probabilidades. Médias seguidas da mesma letra maiúscula na linha e minúscula na coluna não diferem entre si pelo teste de Tukey em 0,05 de probabilidade. 
TABELA 6. Classificação do vigor de plântulas de girassol da cultivar Helio 360 oriundas de cipselas provenientes de três épocas de semeadura (1: 22 jan., 2: 9 jul., 3: 12 jul. 2007) e quatro peneiras (1: 6,0 mm, 2: 5,5 $\mathrm{mm}, 3: 5,0 \mathrm{~mm}, 4: 4,5 \mathrm{~mm})$.

\begin{tabular}{|c|c|c|c|c|c|c|}
\hline \multirow{5}{*}{$\begin{array}{c}\text { Plântulas } \\
\text { normais (\%) }\end{array}$} & \multicolumn{6}{|c|}{ Peneira } \\
\hline & Época & 1 & 2 & 3 & 4 & Médias \\
\hline & 1 & $34,67 \pm 12,22$ & $45,33 \pm 16,65$ & $69,33 \pm 16,16$ & $40,00 \pm 13,86$ & $47,33 \mathrm{a}$ \\
\hline & 2 & $45,33 \pm 20,78$ & $38,67 \pm 15,14$ & $49,33 \pm 18,47$ & $36,00 \pm 4,00$ & $42,33 \mathrm{a}$ \\
\hline & 3 & $41,33 \pm 12,86$ & $50,67 \pm 12,22$ & $52,00 \pm 14,42$ & $37,33 \pm 15,14$ & $45,33 \mathrm{a}$ \\
\hline \multicolumn{2}{|l|}{ Médias } & $40,44 \mathrm{AB}$ & $44,89 \mathrm{AB}$ & $56,89 \mathrm{~A}$ & $37,78 \mathrm{~B}$ & \\
\hline \multicolumn{7}{|c|}{$C V(\%)=31,32 ; W=0,9444(0,0921) ;{ }^{1} F=0,968(0,4988) ;{ }^{2} F=0,847(0,5991) ; F c^{*} p=0,815(0,5689)$} \\
\hline \multirow{5}{*}{$\begin{array}{c}\text { Plântulas } \\
\text { anormais } \\
\text { danificadas (\%) }\end{array}$} & \multicolumn{6}{|c|}{ Peneira } \\
\hline & Época & 1 & 2 & 3 & 4 & Médias \\
\hline & 1 & $5,33 \pm 9,24$ & $14,67 \pm 11,55$ & $9,33 \pm 2,31$ & $10,67 \pm 6,11$ & $10,00 \mathrm{a}$ \\
\hline & 2 & $8,00 \pm 8,00$ & $9,33 \pm 9,24$ & $12,00 \pm 6,93$ & $12,00 \pm 4,00$ & $10,33 \mathrm{a}$ \\
\hline & 3 & $10,67 \pm 2,31$ & $5,33 \pm 6,11$ & $5,33 \pm 2,31$ & $12,00 \pm 10,58$ & $8,33 \mathrm{a}$ \\
\hline Médias & & $8,00 \mathrm{~A}$ & $9,78 \mathrm{~A}$ & $8,89 \mathrm{~A}$ & $11,56 \mathrm{~A}$ & \\
\hline \multicolumn{7}{|c|}{$C V(\%)=76,11 ; W=0,9724(0,5816) ;{ }^{1} F=2,326(0,0407) ;{ }^{2} F=0,529(0,8647) ; F c^{*} p=0,686(0,6625)$} \\
\hline \multirow{5}{*}{$\begin{array}{c}\text { Plântulas } \\
\text { anormais } \\
\text { infectadas (\%) }\end{array}$} & \multicolumn{6}{|c|}{ Peneira } \\
\hline & Época & 1 & 2 & 3 & 4 & Médias \\
\hline & 1 & $60,00 \pm 13,86$ & $40,00 \pm 17,43$ & $20,00 \pm 8,00$ & $42,67 \pm 20,53$ & $40,67 \mathrm{a}$ \\
\hline & 2 & $46,67 \pm 27,23$ & $49,33 \pm 16,65$ & $38,67 \pm 25,40$ & $46,67 \pm 12,22$ & $45,33 \mathrm{a}$ \\
\hline & 3 & $45,33 \pm 8,33$ & $42,67 \pm 16,65$ & $38,67 \pm 20,13$ & $48,00 \pm 24,33$ & $43,67 \mathrm{a}$ \\
\hline Médias & & $50,67 \mathrm{~A}$ & $44,00 \mathrm{~A}$ & $32,44 \mathrm{~A}$ & $45,78 \mathrm{~A}$ & \\
\hline
\end{tabular}

Peneira

\begin{tabular}{lcccccc} 
& Época & 1 & 2 & 3 & 4 & Médias \\
\cline { 2 - 7 } Sementes & 1 & $0 \pm 0$ & $0 \pm 0$ & $1,33 \pm 2,31$ & $6,67 \pm 4,62$ & $2,00 \mathrm{a}$ \\
mortas (\%) & 2 & $0 \pm 0$ & $2,67 \pm 2,31$ & $0 \pm 0$ & $5,33 \pm 9,24$ & $2,00 \mathrm{a}$ \\
& 3 & $2,67 \pm 2,31$ & $1,33 \pm 2,31$ & $4,00 \pm 6,93$ & $2,67 \pm 2,31$ & $2,67 \mathrm{a}$ \\
\hline Médias & $0,89 \mathrm{~A}$ & $1,33 \mathrm{~A}$ & $1,78 \mathrm{~A}$ & $4,89 \mathrm{~A}$ &
\end{tabular}

$C V=174,93 ; W=0,8846(0,0011) ;{ }^{1} F=9,068(0,0001) ; H=9,313(0,593)$

$C V$ : coeficiente de variação; $W$ : estatística do teste de Shapiro-Wilk para normalidade dos resíduos da ANOVA; ${ }^{1} F$ : estatística do teste de Levene; ${ }^{2} F$ : valor da distribuição de Snedecor (ANOVA); $F^{*}{ }^{*}$ : valor de $F$ da distribuição de Snedecor para a interação época*peneira; $H$ : estatística do teste de Kruskal-Wallis. Valores entre parênteses indicam as probabilidades. Médias seguidas da mesma letra maiúscula na linha e minúscula na coluna não diferem entre si pelo teste de Tukey ou Dunn em 0,05 de probabilidade.

O comprimento do hipocótilo e da raiz primária de plântulas de girassol da cultivar Helio 360 independe do tamanho das cipselas, visto que não foram detectadas diferenças entre os tratamentos (Tabela 8). Ferreira e Torres (2000) e Pádua et al.
(2010), estudando sementes de Acacia senegal e sementes de soja das cultivares BRSMG 752S, BRSMG 790A, respectivamente, concluíram que o comprimento médio da raiz primária aumentou com o tamanho das sementes. 
TABELA 7. Plântulas normais fortes (\%) de girassol da cultivar Helio 360 oriundas de cipselas provenientes de três épocas de semeadura (1: 22 jan., 2: 9 jul., 3: 12 jul. 2007) e quatro peneiras (1: 6,0 mm, 2: 5,5 mm, 3: $5,0 \mathrm{~mm}, 4: 4,5 \mathrm{~mm})$.

\begin{tabular}{lcccccc}
\hline & \multicolumn{5}{c}{ Peneira } \\
\cline { 2 - 7 } Plântulas & Época & 1 & 2 & 3 & 4 & Médias \\
\cline { 2 - 6 } normais fortes & 1 & $48,61 \pm 35,44$ & $75,42 \pm 10,48$ & $47,13 \pm 9,19$ & $76,19 \pm 25,08$ & 61,84 a \\
$(\%)$ & 2 & $69,36 \pm 18,78$ & $41,67 \pm 29,09$ & $56,83 \pm 10,00$ & $66,39 \pm 3,76$ & 58,56 a \\
& 3 & $70,90 \pm 25,21$ & $72,64 \pm 17,85$ & $49,21 \pm 15,49$ & $68,44 \pm 29,46$ & 65,29 a \\
\hline Médias & $62,96 \mathrm{~A}$ & $63,24 \mathrm{~A}$ & $51,05 \mathrm{~A}$ & $70,34 \mathrm{~A}$ & \\
\hline$C V(\%)=34,45 ; W=0,9706(0,529) ;{ }^{1} F=1,417$ & $(0,2286) ;{ }^{2} F=1,016$ & $(0,4626) ; F c^{*} p=1,13(0,3754)$ \\
\hline
\end{tabular}

$C V$ : coeficiente de variação; $W$ : estatística do teste de Shapiro-Wilk para normalidade dos resíduos da ANOVA; ${ }^{1} F$ : estatística do teste de Levene; ${ }^{2} F$ : valor da distribuição de Snedecor (ANOVA); $F c^{*} p$ : valor de $F$ da distribuição de Snedecor para a interação época*peneira. Valores entre parênteses indicam as probabilidades. Médias seguidas da mesma letra maiúscula na linha e minúscula na coluna não diferem entre si pelo teste de Tukey em 0,05 de probabilidade.

TABELA 8. Comprimento do hipocótilo $(\mathrm{cm})$ e da raiz primária $(\mathrm{cm})$ de plântulas de girassol da cultivar Helio 360 oriundas de cipselas provenientes de três épocas de semeadura (1: 22 jan., 2: 9 jul., 3: 12 jul. 2007) e quatro peneiras $(1: 6,0 \mathrm{~mm}, 2: 5,5 \mathrm{~mm}, 3: 5,0 \mathrm{~mm}, 4: 4,5 \mathrm{~mm})$.

\begin{tabular}{|c|c|c|c|c|c|c|}
\hline \multirow{5}{*}{$\begin{array}{l}\text { Hipocótilo } \\
\text { (cm) }\end{array}$} & \multicolumn{6}{|c|}{ Peneira } \\
\hline & Época & 1 & 2 & 3 & 4 & Médias \\
\hline & 1 & $2,76 \pm 0,40$ & $3,49 \pm 0,30$ & $3,20 \pm 0,74$ & $3,55 \pm 0,60$ & $3,25 \mathrm{a}$ \\
\hline & 2 & $3,20 \pm 0,57$ & $3,14 \pm 0,04$ & $2,90 \pm 0,35$ & $2,67 \pm 0,39$ & $2,98 \mathrm{a}$ \\
\hline & 3 & $3,07 \pm 0,42$ & $3,45 \pm 0,38$ & $3,41 \pm 0,36$ & $3,32 \pm 0,17$ & $3,31 \mathrm{a}$ \\
\hline \multicolumn{2}{|c|}{ Médias } & $3,01 \mathrm{~A}$ & $3,36 \mathrm{~A}$ & $3,17 \mathrm{~A}$ & $3,18 \mathrm{~A}$ & \\
\hline \multicolumn{7}{|c|}{$\mathrm{CV}(\%)=13,63 ; \mathrm{W}=0,9787(0,7725) ;{ }^{1} \mathrm{~F}=1,904(0,0906) ;{ }^{2} \mathrm{~F}=1,303(0,2814) ; \mathrm{Fc} * \mathrm{p}=1,243(0,3200)$} \\
\hline \multirow{5}{*}{$\begin{array}{c}\text { Raiz } \\
\text { primária } \\
(\mathrm{cm})\end{array}$} & \multicolumn{6}{|c|}{ Peneira } \\
\hline & Época & 1 & 2 & 3 & 4 & Médias \\
\hline & 1 & $6,11 \pm 0,64$ & $4,89 \pm 0,33$ & $6,60 \pm 3,53$ & $6,18 \pm 2,33$ & $5,95 \mathrm{a}$ \\
\hline & 2 & $5,21 \pm 2,46$ & $5,73 \pm 0,37$ & $5,83 \pm 1,23$ & $6,64 \pm 1,01$ & $5,85 \mathrm{a}$ \\
\hline & 3 & $6,93 \pm 0,92$ & $6,39 \pm 0,75$ & $4,75 \pm 0,67$ & $5,63 \pm 1,35$ & $5,93 \mathrm{a}$ \\
\hline \multicolumn{2}{|c|}{ Médias } & $6,08 \mathrm{~A}$ & $5,67 \mathrm{~A}$ & $5,73 \mathrm{~A}$ & $6,15 \mathrm{~A}$ & \\
\hline \multicolumn{7}{|c|}{$\mathrm{CV}(\%)=27,15 ; \mathrm{W}=0,9514(0,1533) ;{ }^{1} \mathrm{~F}=4,3720(0,0012) ; \mathrm{H}=10,8200(0,4585)$} \\
\hline
\end{tabular}

Comparando-se as grandes culturas, há menor quantidade de trabalhos sobre girassol no Brasil, principalmente no tocante à produção e tecnologia de sementes, visto que essa cultura está em processo mais recente de exploração comercial. Isso estimula a retomada de avaliações referentes ao desempenho em função do 
tamanho das cipselas para as diferentes cultivares, à medida que essas forem sendo lançadas no mercado.

Pesquisas sobre o efeito do tamanho de sementes sobre a qualidade fisiológica dessas têm origem na justificativa dada pelos estudiosos da área de que sementes maiores teriam mais reservas e por isso produziriam plântulas mais vigorosas. Atualmente, as espécies cujas sementes são separadas por peneiras como o girassol, o algodão e o milho, são vendidas pela maioria das empresas por número de sementes, pois facilita ao produtor fazer a programação do número de sacas a adquirir, de acordo com a área a ser plantada.

Estudos realizados por Marcos Filho et al. (1986) com as cultivares Anhandy, Contisol e C-33 mostraram que cipselas de girassol de tamanho inferior ao médio do lote, dentro de limites de tolerância baseados no desvio padrão, apresentam tendência de redução da germinação, ou seja, diferença superior a $0,8 \mathrm{~mm}$ em relação à média do lote é suficiente para se detectar alteração no vigor. Contudo, o presente trabalho mostrou que as cipselas da cultivar Helio 360 não modificaram o processo de emergência em função da sua largura, mesmo com uma diferença de 1,5 mm entre a maior e a menor largura estudadas. Informações de campo oriundas de técnicos indicam que diferenças no vigor das plântulas, decorrentes do tamanho das sementes, são detectadas quando no ano agrícola há algum fator limitante para a produção. Como os campos de produção das cipselas da cultivar Helio 360, no ano agrícola de 2007, não apresentaram nenhum fator limitante, torna-se necessário investir em condições de campo para verificar a competição entre plântulas, o que talvez gere diferenças, especialmente decorrentes dos tamanhos diferenciados.

\section{CONCLUSÃO}

$\mathrm{O}$ teor de água e massa seca aos $70{ }^{\circ} \mathrm{C}$ foram influenciados pela época de semeadura e pela largura das cipselas. Cipselas com menor largura $(4,5 \mathrm{~mm})$ tiveram maior teor de água e matéria seca nas épocas 1 e 2 e as de maior largura apresentaram maior teor de água nas épocas 2 e 3. Apenas na época 3 as cipselas de todas as larguras apresentaram teor de água e massa seca estatisticamente iguais. Cipselas de menor largura apresentaram menor porcentagem de plântulas normais.

\section{AGRADECIMENTOS}

Os autores agradecem à CAPES (Coordenação de
Aperfeiçoamento de Pessoal de Nível Superior) pela concessão de bolsa ao primeiro autor e à Dra. Denise Garcia de Santana pelas sugestões e críticas construtivas relacionadas à análise estatística dos dados.

\section{REFERÊNCIAS}

ADAMO, P.E.; SADER, R.; BANZATTO, D.A. Influência do tamanho na produção e qualidade de sementes de girassol. Revista Brasileira de Sementes, v.6, n.3, p.9-14, 1984

AGUIAR, R.H.; FANTINATTI, J.B.; GROTH, D.; USBERTI, R. Qualidade física, fisiológica e sanitária de sementes de girassol de diferentes tamanhos. Revista Brasileira de Sementes, v.23, n.1, p.134-139, 2001.

BACKES, R.L.; SOUZA, A.M.; BALBINOT JUNIOR, A.A.; GALLOTTI, G.J.M.;BAVARESCO, A. Desempenho de cultivares de girassol em duas épocas de plantio de safrinha no Planalto Norte Catarinense. Scientia Agraria, v.9, n.1, p.41-48, 2008.

CARVALHO, N.M.; NAKAGAWA, J. Sementes: ciência, tecnologia e produção. Jaboticabal: FUNEP, 2000. 588p.

CONAB. Companhia Nacional de Abastecimento. Acompanhamento da safra brasileira de grãos: $10^{\circ}$ levantamento de grãos, julho 2010. Brasília: Companhia Nacional de Abastecimento, 2010. 43p.

DAROS, E.; RONZELLI JUNIOR, P. Resposta do girassol à época de semeadura, no primeiro planalto paranaense, safra 92/93. In: Reunião Nacional de Pesquisa de Girassol, 10, Goiânia. Resumos... Campinas: IAC/Embrapa, 1993, p.67.

EMBRAPA. Empresa Brasileira de Pesquisa Agropecuária. Biodiesel é destaque em evento nacional de girassol, 2005. Disponível: $\leq \mathrm{http}$ //www.embrapa.br/imprensa/ noticias/2005>. Acesso em: 26 ago. 2009.

FALEIRO, H.T.; JÚNIOR, R.P.S; SILVA, L.F. Caracterização de grãos de girassol (Hellianthus annuus L.) ao longo do período de colheita em dois municípios do Estado de Goiás. Pesquisa Agropecuária Tropical, v.31, n.2, p.163-168, 2001.

FERREIRA, M.G.R.; TORRES, S.B. Influência do tamanho das sementes na germinação e no vigor de plântulas de Acacia senegal (L.) Willd. Revista Brasileira de Sementes, v.22, n.1, p.271-275, 2000.

GASPAR, C.M.; NAKAGAWA, J. Teste de condutividade elétrica em função do período e da temperatura de embebição para sementes de milheto. Revista Brasileira 
de Sementes, v.24, n.2, 2002.

LEDO, A.S.; MEDEIROS-FILHO, S.; LEDO, F.J.S.; ARAÚJO, E.C. Efeito do tamanho de semente, do substrato e pré-tratamento em sementes de pupunha. Ciência Agronômica, v.33, n.1, p.29-32, 2002.

LEISHMAN, M.R.; WESTOBY, M. The role of seed size in seedling establishment in dry soil conditions experimental evidence from semi-arid species. Journal of Ecology, v.82, n.2, p.249-258, 1994.

LEITE, R.M.V.B. Manejo de doenças do girassol. In: LEITE, R.M.V.B.; BRIGHENTI，A.M.; CASTRO, C. Girassol no Brasil. Londrina: Embrapa Soja, 2005. p.501546.

MARCOS FILHO, J.; KOMATSU, Y.H.; NOVEMBRE, A.D.L.C.; FRATIN, P.; DEMÉTRIO, C. G.B. Tamanho da semente e desempenho do girassol: III. Comportamento das plantas em campo. Revista Brasileira de Sementes, v.8, n.2, p.33-43, 1986.

MARZINEK, J.; DE-PAULA, O.C.; OLIVEIRA, D.M.T. Cypsela or achene? Refining terminology by considering anatomical and historical factors. Revista Brasileira de Botânica, v.31, n.3, p.549-553, 2008.

NAKAGAWA, J. Testes de vigor baseados na avaliação das plântulas. In: VIEIRA, R.D.; CARVALHO, N.M. Testes de vigor em sementes. Jaboticabal: FUNEP, p.4985, 1994.

OLIVEIRA, A.B.; MEDEIROS-FILHO, S.; BEZERRA, A.M.E.; BRUNO, R.L.A. Emergência de plântulas de Copernicia hospita martius em função do tamanho da semente, do substrato e ambiente. Revista Brasileira de Sementes, v.31, n.1, p.281-287, 2009.

PÁDUA, G.P.; ZITO, R.K.; ARANTES, N.E.; FRANÇA NETO, J.B. Influência do tamanho da semente na qualidade fisiológica e na produtividade da cultura da soja. Revista Brasileira de Sementes, v.32, n.3, p.09-16, 2010.
PORTO, W.S.; CARVALHO, C.G.P.; BARTH PINTO, R.J. Adaptabilidade e estabilidade como critérios para seleção de genótipos de girassol. Pesquisa Agropecuária Catarinense, v.42, p.491-499, 2007.

RAMOS, J.G. Efeito de seis épocas de plantio em três híbridos de girassol, em Senador Canedo, Estado de Goiás. In: REUNIÃO NACIONAL DE PESQUISA DE GIRASSOL, 11., 1995. Goiânia. Resumos... Goiânia: Embrapa/CNPAF, EMGOPA, 1995, p.23.

RANAL, M.A.; SANTANA, D.G. How and why to measure the germination process? Revista Brasileira de Botânica, v.29, n.1, p.1-11, 2006.

SANGOI, L.; KRUSE, N.D. Comportamento de cultivares de girassol em diferentes épocas de semeadura no planalto catarinense. Pesquisa Agropecuária Brasileira, v.28, n.1, p.81- 91, 1993.

SANTOS, C.M.; SILVA, E.V.; SANTOS, V.L.M.; JULIATTI, F.C. Qualidade de sementes do algodão (Gossypium hirsutum L.), em função do tamanho e do local de produção. Revista Brasileira de Sementes, v.23, n.2, p.144-151, 2001.

SOLASI, A.D.; MUNDSTOCK, C.M. Época de semeadura e características do capítulo de cultivares de girassol. Pesquisa Agropecuária Brasileira, v.27, n.6, p.873-879, 1992.

TOMICH, T.R.; RODRIGUES, J.A.S.; GONÇALVES, L.C.; TOMICH, R.G.P.; CARVALHO, A. U. Potencial forrageiro de cultivares de girassol produzidos na safrinha para ensilagem. Arquivo Brasileiro de Medicina Veterinária e Zootecnia, v.55, n.6, p.756-762, 2003.

UNGARO, M.R.G.; NOGUEIRA, S.S.S.; NAGAI, V. Parâmetros fisiológicos, produção de aquênios e fitomassa de girassol em diferentes épocas de cultivo. Bragantia, v.59, n.2, p.205-211, 2000. 